Article

\title{
Luminescence of CsI and CsI:Na Films under LED and X-ray Excitation
}

\author{
Jin-Cherng Hsu ${ }^{1,2, *}$ and Yu-Shen Ma ${ }^{2}$ \\ 1 Department of Physics, Fu Jen Catholic University, No.510 Zhongzheng Rd., Xinzhuang Dist., \\ New Taipei City 24205, Taiwan \\ 2 Graduate Institute of Applied Science and Engineering, Fu Jen Catholic University, No. 510 Zhongzheng Rd., \\ Xinzhuang Dist., New Taipei City 24205, Taiwan; ma0309@livemail.tw \\ * Correspondence: 054326@mail.fju.edu.tw; Tel.: +886-2-29053765; Fax: +886-2-29021038
}

Received: 27 October 2019; Accepted: 11 November 2019; Published: 13 November 2019

check for updates

\begin{abstract}
In this study, we investigated the luminous properties of undoped cesium iodide (CsI) and Na-doped CsI (CsI:Na) films deposited by thermal vacuum evaporation and treated with different substrate temperatures, post-annealing temperatures, and deposition rates. The quality of the deposited films was evaluated by their XRD pattern, SEM cross-section/surface morphologies and UV/X-ray luminescence, the spectra of which were used to derive the luminescence mechanism of the deposited films. The $310 \mathrm{~nm}$ luminescence demonstrates that the exciting light arises from the electron-hole recombination through the self-trapped exciton (STE) process, which is characteristic of the host polycrystalline CsI. The broad-band luminescence from $\sim 400$ to $450 \mathrm{~nm}$ demonstrates the other electron-hole recombination between the new energy states created by doping $\mathrm{Na}$ in the forbidden gap of CsI. When we deposited higher quality films at a substrate temperature of $200^{\circ} \mathrm{C}$, the undoped CsI films showed preferred crystal orientation at (200), and the CsI:Na films co-evaporated by $1 \mathrm{wt.} \% \mathrm{NaI}$ at (310) and had the highest UV/X-ray luminescence.
\end{abstract}

Keywords: cesium iodide; CsI:Na; UV luminescence; X-ray-excited luminescence

\section{Introduction}

Undoped cesium iodide (CsI) has been widely used for efficient scintillation [1,2] because cesium (Cs) and iodide (I) have high atomic numbers and large stopping power [3,4]. It strongly absorbs UV light, $\mathrm{X}$-rays, and gamma-rays and presents very fast luminescence emission on the order of $10 \mathrm{~ns}$ [5-8]. When excited by a higher-energy photon, some of the electrons in the valence band jump over the forbidden gap to the conduction band. In the de-excitation process of the larger width of the forbidden gap, the photons emit UV light in the energy region of 3.7 to $4.3 \mathrm{eV}[9,10]$. An energy state is generated in the forbidden gap by adding sodium (Na) or thallium (Tl) dopant to the CsI film to convert X-rays and gamma rays into visible light and to increase the luminescent effect [11,12]. Thus, the excited CsI:Na films emit a visible blue light of about $3 \mathrm{eV}(\lambda=431 \mathrm{~nm})$ that shows recombination of the primary emission of CsI disturbed by the dopants $[9,11]$.

The luminescence properties and preferred crystal orientations are different because of the different fabrications and thicknesses of the films [13]. In our research, the problem of different crystal orientations has also plagued us for many years [14-17]. However, the complicated preferred peaks for CsI crystal are (110), (200), (211), (220), (310), (222), and (321). The lattice planes corresponding to the CsI powder are (110), (200), (211), (220), (310), (222), and (321) [18,19].

In our previous studies, we successfully mixed CsI powder with a small amount of NaI co-evaporated by thermal vacuum deposition because the boiling point of $\mathrm{NaI} 1304 \pm 5{ }^{\circ} \mathrm{C}$ is near that of CsI $1277 \pm 5^{\circ} \mathrm{C}[19,20]$. However, moisture can significantly alter the alkaline halide 
structure [14]. The luminescent light from the film then spreads and broadens, resulting in a reduction in the resolution of the image used as an X-ray image converter [21]. Furthermore, the nanoparticles of $\mathrm{NaI}$ are more hygroscopic in the air than other alkali halides. An anti-moisture process after the deposition process of CsI:Na film is necessary because the hygroscopic nanoparticles remarkably decrease the luminescence scintillation and generate cracks in the cylindrical structure [9,12,22-25]. In previous studies, the protective $\mathrm{SiO}_{2}, \mathrm{Al}$, and parylene-N layers subsequently deposited on the CsI or CSI:Na film in the same vacuum chamber was investigated, respectively $[14-17,19]$. The parylene-N layer can protect the films as a columnar structure. In this paper, we studied the scintillation mechanism of CsI:Na films from their optical and structural properties.

The nature of the inherent luminescence and the mechanism of CsI have been studied since the twentieth century [26-28]. The luminescence process is due to the attenuation of two types of self-capturing excitons (STE) $[5,9,10,27]$. One is the on-center STE, the electrons of which were captured at $\mathrm{V}_{\mathrm{k}}$ - centers at room temperature. The other is the off-center STE with $\mathrm{F}$-and $\mathrm{H}$-center pairs formed by the molecular ion $\mathrm{I}_{2}{ }^{-}$at a temperature of less than $100 \mathrm{~K}$ [29]. Adiabatic potential energy surface (APES) indicates the variation of the luminescence spectra with temperatures resulting from the re-distribution of the electron population between on- and off-center STEs. The Onsager mechanism has also been used to describe the temperature dependence of the scintillation light $[30,31]$. The CsI and CsI:Na scintillators emit photons with a wavelength between 280 and $350 \mathrm{~nm}$ in the de-excitation process, according to the evidence of some investigations summarized in Table 1. In spite of the higher excitation energy of Am-241 gamma rays [32] or the lower excitation energy of $277 \mathrm{~nm}$ UV light [33], the emission of STE was still within the range 285 to $435 \mathrm{~nm}$. This study shows that the wavelength of the STE with interference from the sodium dopant is longer than that of the undisturbed STE because sodium activators produce energy levels after Na doping in CsI film. That is discussed in Section 3.4.

Table 1. Emission wavelengths of undoped cesium iodide (CsI) and Na-doped CsI (CsI:Na) scintillator reported in the literature. Self-trapped exciton, STE.

\begin{tabular}{ccccc}
\hline Scintillator & Excited Method & Temperature & Wavelength (nm) & STE Style \\
\hline undoped & two-photon absorption & $4.5 \mathrm{~K}-\mathrm{RT}^{1}$ & $288-335$ & on-center [9] \\
of 3.18 eV light & $\mathrm{CL}$ & $\mathrm{RT}$ & 305,315 & on-center [34] \\
undoped & X-ray & $50 \mathrm{~K}-\mathrm{RT}$ & $285-340$ & on-center [8] \\
undoped & $\mathrm{RT}$ & 310 & STE [32] \\
doped Na & $\mathrm{PL}$ 265 nm/CL & $\mathrm{RT}$ & 315 & STE [8,34] \\
doped Na & $\mathrm{CL}$ & $\mathrm{RT}$ & 305 & on-center [8] \\
doped Na & X-ray & $80 \mathrm{~K}$ & $288 / 335$ & STE [35] \\
doped Na & X-ray & $4 \mathrm{~K}$ & 290 & {$[10]$} \\
doped Na & X-ray & $77 \mathrm{~K} / \mathrm{RT}$ & $344 / 420$ & on/off center [9] \\
doped Na & 217-277 nm UV & $\mathrm{LN}{ }^{3} / \mathrm{RT}$ & $350 / 435$ & {$[33]$} \\
\hline
\end{tabular}

${ }^{1}$ Room temperature; ${ }^{2}$ Cathode luminescence; ${ }^{3}$ Liquid nitrogen temperature.

Furthermore, the separating column structure of CsI film, which suppresses lateral light scattering due to the total internal reflection from their boundary surfaces, can be used as light guides for the scintillation light generated by $X$-ray excitation to increase the spatial resolution of the X-ray image [36]. In this study, the higher deposition rate also promotes the formation of columnar structure and higher packing density of the films. The deposited films preferably have not only a columnar structure but also moisture resistance [37].

\section{Materials and Methods}

The CsI and CsI:Na films can be evaporated out of a box-type molybdenum boat $\left(15 \times 20 \times 70 \mathrm{~mm}^{3}\right)$ with a perforated cover. The undoped CsI powder or its mixture with $0.5,1$, or $2 \mathrm{wt} . \% \mathrm{NaI}$ powder, with a total weight of about $50 \mathrm{~g}$, was placed in the boat. Before the vacuum, thermally resistant evaporation, 
B270 glasses and silicon wafers were cleaned with alcohol in an ultrasonic bath, blow-dried with dry nitrogen gas, and then placed in a substrate holder positioned approximately $25 \mathrm{~cm}$ above the boat.

The chamber was evacuated to a base pressure of $4 \times 10^{-6}$ Torr by using a diffusion pump. The molybdenum boat was preheated with a current of about 50 A with a 12 VAC power supply for about $30 \mathrm{~min}$ to outgas the evaporated material. The moisture released from the mixture of deposited CsI and NaI materials reduced the oxygen composite in the films. The vacuum pressure lightly increased during the preheating process. The outgas process finished when the pressure decreased again to the base pressure with continuous pumping. The molybdenum boat was then heated using an electric current of about $200 \mathrm{~A}$ to deposit the films.

We divided the experimental results into four parts with thicknesses ranging about 5 to $\sim 176 \mu \mathrm{m}$ and at deposition rates ranging from 3 to $110 \mathrm{~nm} / \mathrm{sec}$, as shown in Table 2. The thicknesses were about $15 \mu \mathrm{m}$ in Part 4, as the substrate platform was rotated during the deposition, and the evaporation source was about $100 \mathrm{~mm}$ away from the axis of rotation to achieve thickness uniformity.

Table 2. CsI:Na films deposited at various parameters.

\begin{tabular}{ccccc}
\hline Part & NaI (wt.\%) & Deposition Rate $(\mathbf{n m} / \mathbf{s e c})$ & Thickness $(\boldsymbol{\mu m})$ & Reference \\
\hline 1 & $0,1,10$ & $3-5$ & $\sim 5$ & {$[17]$} \\
2 & 0,1 & $30,50,70,90,110$ & $\sim 8$ & {$[37]$} \\
3 & $0,0.5,1,2$ & $10-20$ & $70-176$ & {$[14,16]$} \\
4 & $0,0.5,1,2$ & $20-25$ & $\sim 15$ (rotation) & {$[15]$} \\
\hline
\end{tabular}

These as-deposited films were labeled with $\mathrm{CsI}: \mathrm{Na}(x \%)$, where $x$ (values from $0.5,1$, to 2 ) is the weight percentage ( $\mathrm{wt} . \%)$ of the amount of co-evaporated material in NaI. The substrate temperature $\left(T_{\mathrm{s}}\right)$ or post-annealing temperature $\left(T_{\mathrm{p}}\right)$ in the vacuum was room temperature (RT) to $300{ }^{\circ} \mathrm{C}$. The post-annealing process increased the temperature rate by about $15^{\circ} \mathrm{C} / \mathrm{min}$, and we kept the final temperature for one hour and then naturally cooled it to room temperature.

By preventing the hygroscopic CsI:Na films from absorbing the moisture in the atmosphere, we sequentially evaporated a parylene-N layer on the films in the same vacuum chamber, using the thermal decomposition method. A homemade ceramic evaporator boat $10 \times 10 \times 40 \mathrm{~mm}^{3}$ in size was covered with a perforated molybdenum foil [15]. Before the pumping of the vacuum chamber, the parylene-N dimer $\sim 5 \mathrm{~g}$ was transferred into the ceramic evaporator boat. During the thermal decomposition process, the dimer was sublimated by thermal radiation from the perforated Mo foil heated by a high electric current of $100 \mathrm{~A}$ and was pyrolyzed into a monomer $[38,39]$ through the small holes of the foil. The monomer vapor formed a polymer on the surface of the CsI:Na film. The polymer layer was deposited at about $1 \mu \mathrm{m}$ thickness at a rate of $\sim 0.7 \mathrm{~nm} / \mathrm{sec}$ and a working pressure of $8 \times 10^{-4}$ Torr.

The samples were investigated by a Fourier transform infrared (FTIR) spectrometer Perkin-Elmer 100 (Perkin Elmer, Inc., Waltham, MA, USA) from 3250 to $3750 \mathrm{~cm}^{-1}$ to measure the moisture absorption on the films. Morphologies of the surfaces and cross-sections of the films were observed by a scanning electron microscope (SEM) Hitachi S-3400N (Hitachi Ltd., Chiyoda-ku, Tokyo, Japan). An X-ray diffractometer Rigaku Multiflex (Rigaku Co., Spring, TX, USA) was used to obtain the sample's X-ray diffraction (XRD) patterns. The luminescence properties of the films were measured by using a PL system with a $275 \mathrm{~nm}$ UV LED (LG Innotek Co., Jung-gu, Seoul, Korea) built in-house, as shown in Figure 1. 


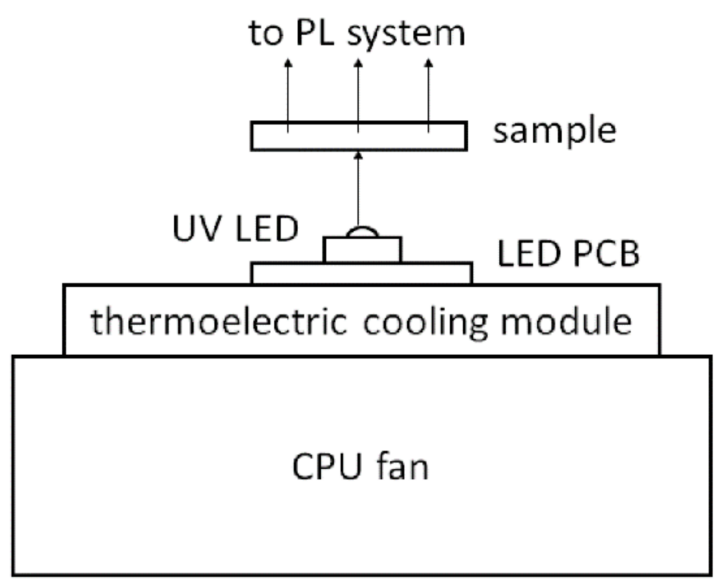

Figure 1. Schematic of homemade PL system with UV LED.

The LED source was driven by the forward voltage of 8 VDC and cooled down by a thermoelectric cooling module with a CPU fan to keep the operating temperature less than $60{ }^{\circ} \mathrm{C}$. The UV LED provides a flux of $10 \mathrm{~mW}$, more radiant than that of a PL (photoluminescence) system derived by a monochromator, and its FWHM of $12.0 \mathrm{~nm}$ is narrower than that of a general UV light source. The X-ray luminescence spectra of the samples were collected using a homemade $\mathrm{X}$-ray excitation luminescence system, as shown in Figure 2. We put the sample on the XRD hollow stage of the X-ray diffractometer Rigaku Multiflex. The sample film was placed face down on the stage. The incident angle of the irradiating X-ray was about $45^{\circ}$. The emitting luminescence from the film was collected by a UV collimating lens to be analyzed using a spectrometer USB2000 (Ocean Optics, Inc., Largo, FL, USA).

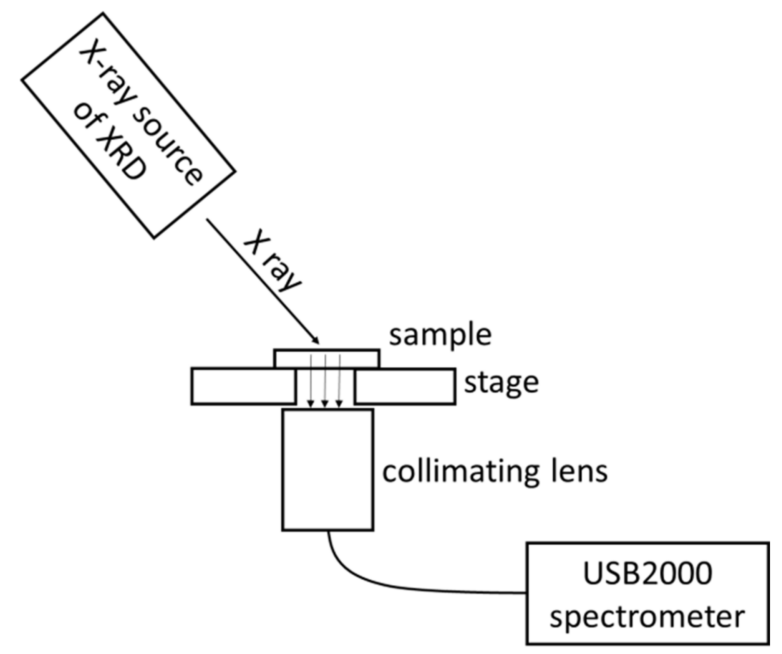

Figure 2. Schematic of the luminescence system built in-house with an X-ray source of a Rigaku X-ray diffractometer.

\section{Results and Discussion}

\subsection{Columnar Structure}

In this study, the heating substrate temperature $\left(T_{\mathrm{S}}\right)$ is an important factor that determines the orientation of the polycrystalline film. The very clear nucleation of the CsI polycrystalline in the orientation results from low surface energy during deposition [12,23]. The CsI films were deposited at $<0.1$ mTorr without a heating substrate. Its cross-section as shown in Figure 3a illustrates the complex fabric structure Zone T of the Thornton model at $T_{\mathrm{s}} / T_{\mathrm{m}}$ ratio $=0.35$, where $T_{\mathrm{m}}$ is the melting point of $600{ }^{\circ} \mathrm{C}(894 \mathrm{~K})$ of the CsI material [40]. With the increase in $T_{\mathrm{s}}$ to $200^{\circ} \mathrm{C}(473 \mathrm{~K})$, the cross-section 
in Figure $3 \mathrm{c}$ shows the simpler columnar structure as Zone II at $T_{\mathrm{s}} / T_{\mathrm{m}}$ ratio $=0.53$. The complex fabric structure having a saw-tooth multi-layer surface shown in Figure $3 \mathrm{~b}$ is rougher than the simple structure having a grainy texture shown in Figure 3d.

Cesium iodide is the ionic compound of cesium and iodine and a deliquescent material. When the film reacts with moisture in the air, its luminescence property greatly decreases. Moreover, many cracks on the film's surface enhance moisture absorption due to capillary action. The cracks result from the film's stress, as shown by XRD in Section 3.3.3. We found that various deposited materials, such as $\mathrm{SiO}_{2}, \mathrm{Al}$, and parylene-N, act as a protective layer against moisture. Large cracks appear on the surface, as shown in Figure $4 \mathrm{a}$, because of the reduced flexibility of the inorganic $\mathrm{SiO}_{2}$ film. The aluminum metal film has good ductility but fills the cracks incompletely, as shown in Figure $4 \mathrm{~b}$. The cracks hardly appear on the protective layer of parylene-N shown in Figure 4c. The moisture resistance of the aluminum layer is less than that of the parylene-N layer, as shown in Section 3.2.

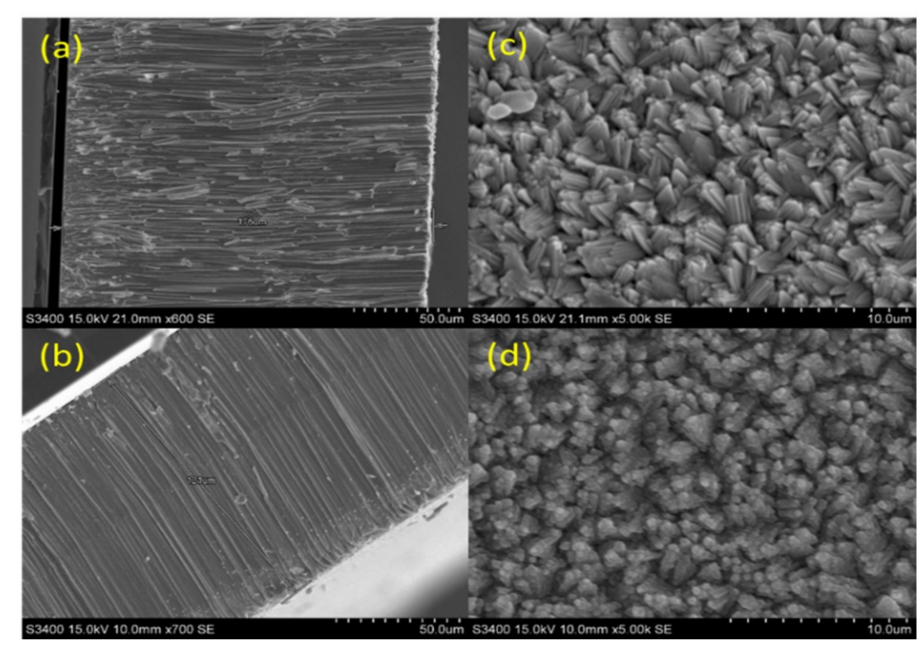

Figure 3. (a) The cross-section and (b) surface morphologies of the CsI film deposited at a thickness of $176 \mu \mathrm{m}$ without heating; (c) The cross-section and (d) surface morphologies of the CsI film deposited at a thickness of $120 \mu \mathrm{m}$ deposited at a substrate temperature of $200{ }^{\circ} \mathrm{C}$.

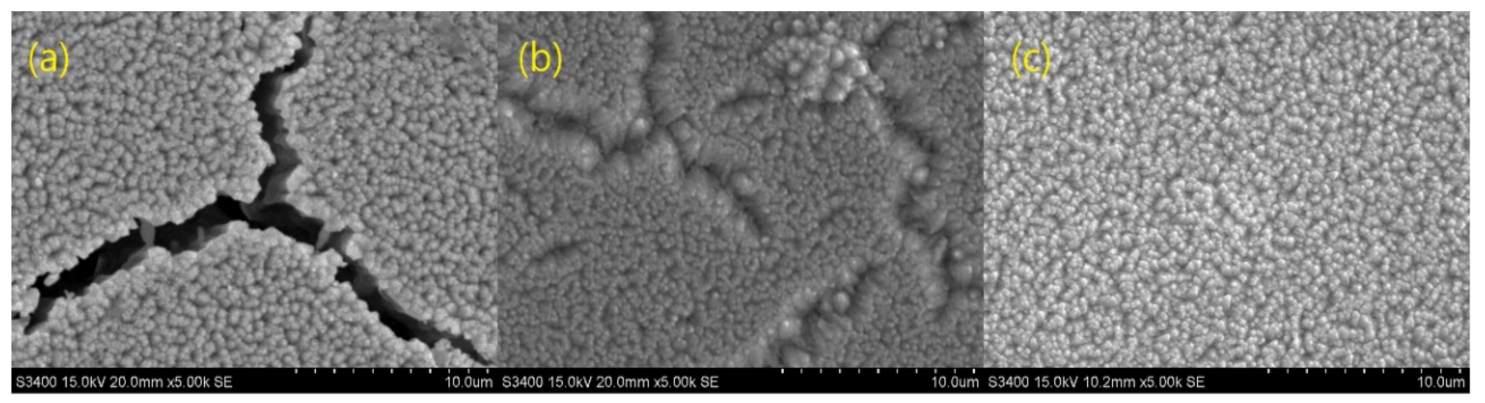

Figure 4. The CsI films protected by (a) $\mathrm{SiO}_{2}$ layer, (b) Al layer, and (c) parylene-N layer.

The Na dopant strongly influences the CsI structure, inhibits the poly-crystallinity, and becomes more hygroscopic. Figure 5 shows that the CsI:Na films have various columnar structures and surface morphologies with various amounts of $\mathrm{Na}$ dopant. The $\mathrm{Na}$ dopant of $\mathrm{CsI}: \mathrm{Na}(0.5 \%)$ has apparently changed the surface shown in Figure 5a and cross-section shown in Figure 5b. CsI:Na(1\%) (Figure 5c) exhibits an obvious poly-crystalline structure compared with the smooth $\mathrm{CsI}: \mathrm{Na}(0.5 \%)$ (Figure $5 \mathrm{a}$ ) and the condensing CsI: $\mathrm{Na}(2 \%)$ (Figure 5e). Moreover, $\mathrm{CsI}: \mathrm{Na}(1 \%)$ (Figure $5 \mathrm{~d}$ ) exhibits a columnar structure more pronounced than that of $\mathrm{CsI}: \mathrm{Na}(0.5 \%)$ (Figure $5 \mathrm{~b}$ ) and CsI:Na(2\%) (Figure 5f). The aggregate structure of $\mathrm{CsI}: \mathrm{Na}(2 \%)$ results from more moisture penetrating the columnar structure. 


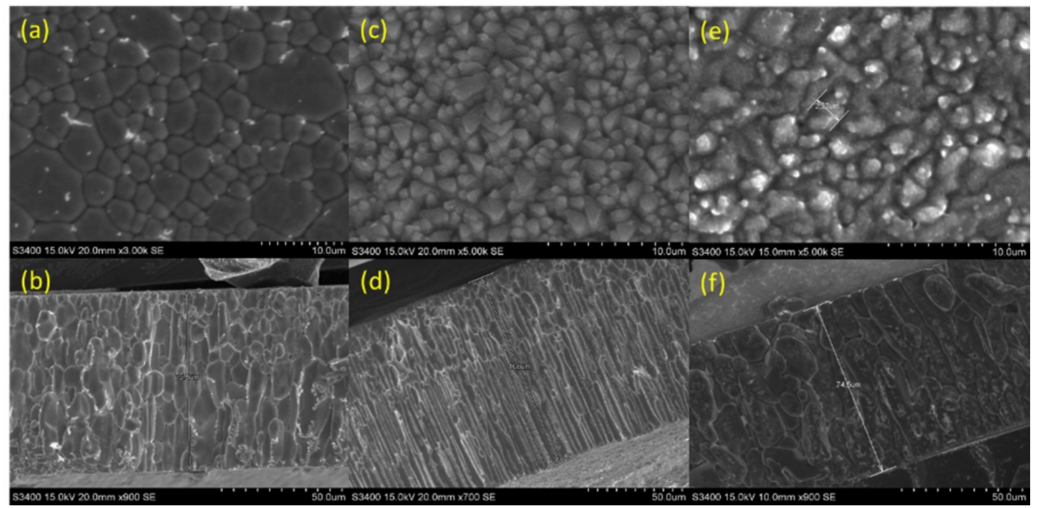

Figure 5. SEM cross-sections of (a) CsI: $\mathrm{Na}(0.5 \%)$, (c) CsI:Na(1\%), and (e) $\mathrm{CsI}: \mathrm{Na}(2 \%)$ and the respective surface morphologies of (b) CsI:Na(0.5\%), (d) CsI:Na(1\%), and (f) CsI:Na(2\%).

\subsection{Moisture Absorption}

Figure 6 shows the composites measured by an energy dispersive spectrometer (EDS). The undoped CsI film not only has equal amounts of cesium (40.31 at.\%) and iodide (39.53 at.\%) but also has oxygen (5.46 at.\%), as shown by the absorbed moisture [15]. During the thermal deposition process, the combination ratio of the two atoms of the CsI film remains almost the same. The 5.46 at.\% oxygen may show the hygroscopicity of the CsI film. It also shows that the CsI film contains a $\mathrm{CsIO}_{3}$ species. Cesium atoms may react with $\mathrm{H}_{2} \mathrm{O}$ that comes from the deposited powder or the deposition vacuum chamber, as shown by the XRD pattern in the next section.

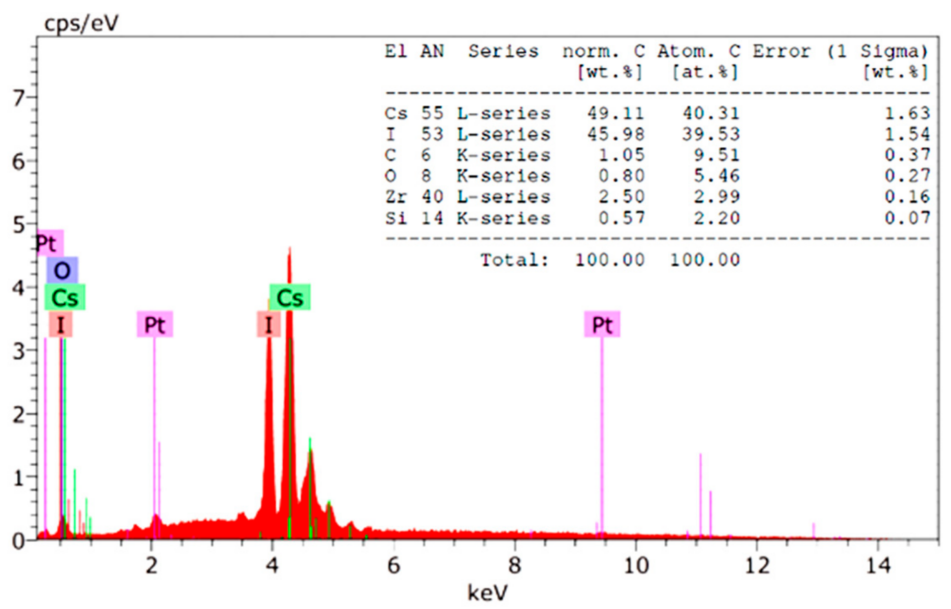

Figure 6. Chemical composition of CsI films measured by EDS spectroscopy.

Figure 7a shows the forming block aggregation structure of the CsI films protected by the $\sim 1 \mu \mathrm{m}$ aluminum layer when exposed to air from 1 to 50 days. The CsI films protected by the parylene-N layer remain in the columnar structure of $\sim 3 \mu \mathrm{m}$ and have a thickness of $\sim 14 \mu \mathrm{m}$ as shown in Figure $7 \mathrm{~b}$. Parylene-N exhibits hydrophobic surface properties, relatively low gas permeability, transparency at wavelengths above $400 \mathrm{~nm}$, and relatively high tensile strength in the temperature range of -200 to $200{ }^{\circ} \mathrm{C}$. The high compliance and stability properties make parylene- $\mathrm{N}$ an ideal protective layer for CsI film affected by moisture [41]. However, a porosity column structure of the CsI films shown in Figure $7 \mathrm{~b}$ still absorb moisture, which can be measured by FTIR because of the $\sim 3500 \mathrm{~cm}^{-1}$ infrared absorption by the water in the film. In Figure $8 \mathrm{a}, T_{0}$ is the transmittance value of the film containing no moisture between the two peaks of the transmittance curve, and $T$ is the lowest transmittance at $\sim 3500 \mathrm{~cm}^{-1}$ of the film containing moisture. 
(a)

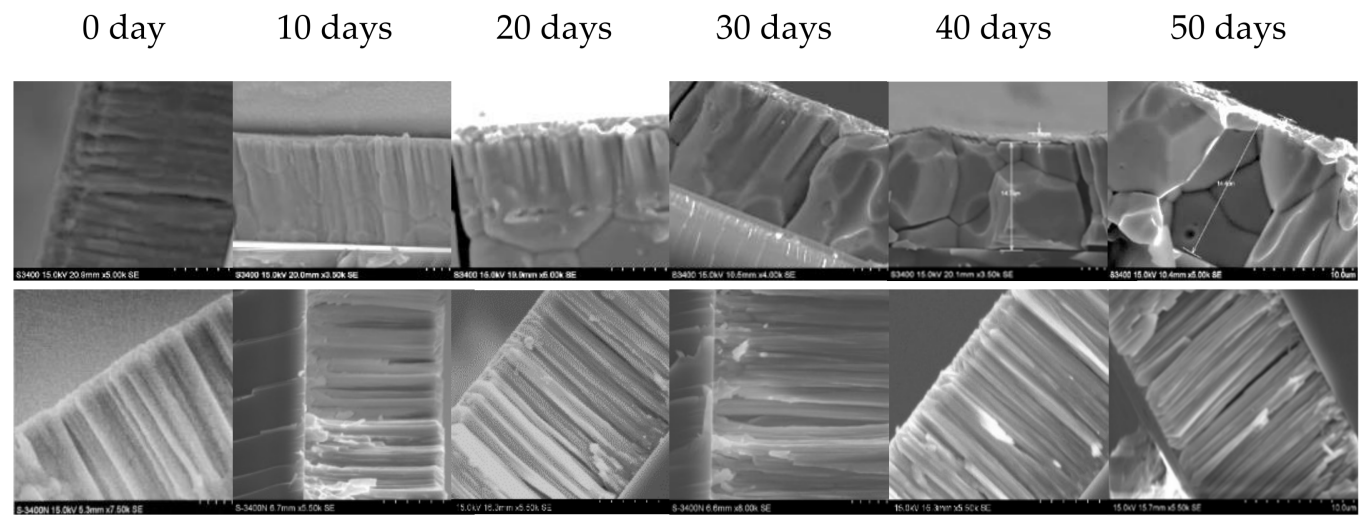

Figure 7. SEM cross-section morphologies of the CsI films exposed to air for 50 days, with protective layers of (a) $\sim 1 \mu \mathrm{m} \mathrm{Al}$ and (b) $\sim 1 \mu \mathrm{m}$ parylene-N.

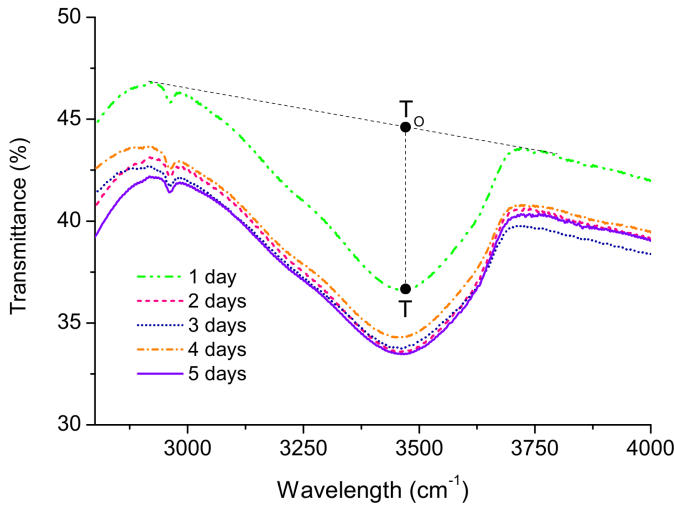

(a)

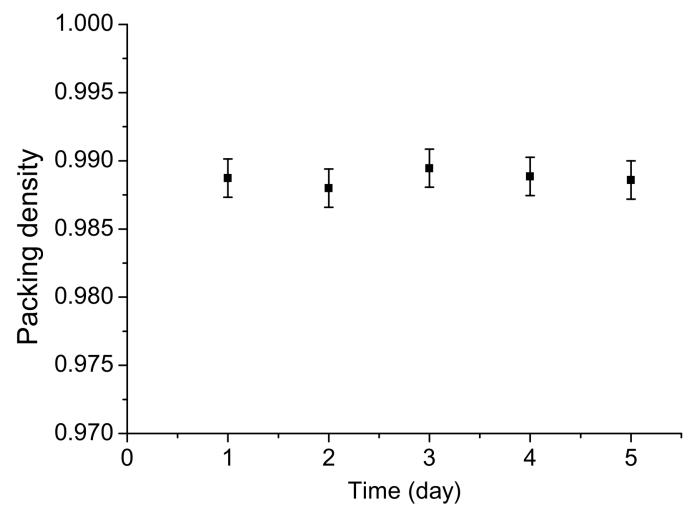

(b)

Figure 8. (a) FTIR spectrum and (b) Packing density of CsI films protected by parylene-N film exposed to air for 5 days.

The density of water $\left(p_{\mathrm{w}}\right)$ in the film can be determined by the following correlation formula [42,43]:

$$
p_{\mathrm{w}}=\frac{\ln \left(T_{0} / T\right)}{\alpha_{\mathrm{w}} d_{\mathrm{f}}}
$$

where $\alpha_{\mathrm{w}}$ is the water vapor absorption rate of $1.27 \times 10^{4} \mathrm{~cm}^{-1}$ at $\sim 3500 \mathrm{~cm}^{-1}$, and $d_{\mathrm{f}}$ is the film thickness. Figure 8a shows the FTIR spectrum of the undoped CsI film exposed to air for 5 days. The packing density $(p)$ is the density of the film at the ratio of the volume occupied by the bulk film to the total film's volume, which can be expressed as follows:

$$
p=1-p_{\mathrm{W}}=1-\frac{\ln \left(T_{0} / T\right)}{\alpha_{\mathrm{w}} d_{\mathrm{f}}}
$$

Figure $8 \mathrm{~b}$ shows that the packing density is stable at $0.98847 \pm 0.000419$ on average when the sample is exposed to air for 5 days. In our previous study, the packing density of the CsI film without a protective layer quickly decreases to 0.745 for 5 days [20]. That is, the parylene-N layer successfully prevents moisture intrusion of the CsI film. It can be proved by XRD in Section 3.3.2 that less $\mathrm{Cs}_{2} \mathrm{O}$ is formed on the surface of the element cesium oxidized after exposure to the air [44]. 


\subsection{X-ray Diffraction Affected by Heat, Thickness, and Na Dopant}

The CsI powder exhibits complex crystalline orientations along the (110), (200), (211), (220), (310), (222), and (321) planes [17]. The primary crystalline orientations are at (110) [18]. CsI and CsI:Na films have many crystalline orientations. Table 3 shows the primary crystalline orientations for distinguishing the polycrystalline properties of the films. A decrease in the number of crystalline orientations regularly occurs in the deposition process. Triloki et al. investigated the CsI films deposited at thicknesses of 4 to $500 \mathrm{~nm}$ from the single crystalline orientation (110) to the complex crystalline orientations of (110), (200), (211), (220), and (321). The thickness clearly affects the crystalline orientations of the film $[44,45]$.

Table 3. All primary XRD peaks of the CsI:Na films deposited with various parameters.

\begin{tabular}{|c|c|c|c|c|c|}
\hline Part & NaI (wt.\%) & $\begin{array}{l}\text { Thickness } \\
(\mu \mathrm{m})\end{array}$ & $\begin{array}{c}\text { Deposition Rate } \\
\text { (nm/sec) }\end{array}$ & Temperature $\left({ }^{\circ} \mathrm{C}\right)$ & Primary XRD \\
\hline \multirow{6}{*}{1} & \multirow{5}{*}{0} & \multirow{6}{*}{5} & \multirow{6}{*}{$3-5$} & without heating & $(200)$ \\
\hline & & & & $T_{\mathrm{p}}: 100,150,200,250,300$ & $(200)$ \\
\hline & & & & $T_{\mathrm{s}}: 100$ & $(200)$ \\
\hline & & & & $T_{\mathrm{s}}: 150,200,250$ & $(110)$ \\
\hline & & & & $T_{\mathrm{s}}: 300$ & $(200)$ \\
\hline & 1,10 & & & without heating & $(211)$ \\
\hline \multirow{5}{*}{2} & \multirow{2}{*}{0} & \multirow{5}{*}{8} & $30,50,70,90,110$ & without heating & $(200)$ \\
\hline & & & 30 & $T_{\mathrm{p}}: 150,200,250,300$ & $(200)$ \\
\hline & \multirow{3}{*}{1} & & $30,50,70,110$ & \multirow{2}{*}{ without heating } & $(310)$ \\
\hline & & & 90 & & (211) \\
\hline & & & 30 & $T_{\mathrm{p}}: 150,200,250,300$ & (310), (200) \\
\hline \multirow{4}{*}{3} & 0 & $176^{*}$ & 25 & without heating & (211) \\
\hline & $0,0.5$ & 70,120 * & 25 & $T_{\mathrm{s}}: 200$ & $(200)$ \\
\hline & 1 & 70 & 25 & $T_{\mathrm{s}}: 150$ & $(200)$ \\
\hline & 1,2 & 70 & 25 & $T_{\mathrm{s}}: 200$ & $(310)$ \\
\hline \multirow{2}{*}{4} & $0,0.5$ & 12 & 20 & $T_{\mathrm{s}}: 150,170,200$ & $(200)$ \\
\hline & 1,2 & 12 & 20 & $T_{\mathrm{s}}: 170,200$ & $(310)$ \\
\hline
\end{tabular}

$T_{\mathrm{p}}$ : deposited without heating and then post-annealed at vacuum; $T_{\mathrm{s}}$ : deposited at substrate temperature. ${ }^{*}$ The samples of SEM morphologies are shown in Figure 3.

\subsubsection{XRD of Undoped CsI Film}

In our studies, the CsI deposited films with thicknesses much larger than $500 \mathrm{~nm}$ exhibit different crystalline orientations of (110), (200), (211), and (310) according to the deposition process. From the experimental data of Part 1 , the primary peak (200) appears without heating, at $T_{\mathrm{p}}$ from 100 to $300{ }^{\circ} \mathrm{C}$, and at $T_{\mathrm{s}} 100$ and $300{ }^{\circ} \mathrm{C}$ conditions. The primary peak (110) only shows at a lower thickness of $5 \mu \mathrm{m}$ at $T_{\mathrm{s}} 150-250{ }^{\circ} \mathrm{C}$ in our studies. With the increase in the CsI thickness to $8 \mu \mathrm{m}$ in Part 2, the primary peak tends to (200) without heating and in the $T_{\mathrm{p}}$ processes. Increasing the thickness to greater than $70 \mu \mathrm{m}$ and decreasing the deposition rates to $25 \mathrm{~nm} / \mathrm{sec}$ can reduce the loss of the evaporated material during the deposition process in Part 3. The primary peak (211) changes to (200) with Ts such that the thermal energy may improve the film's crystallinity. Compared with Figure 3, the film of the primary peak (211) without heating shows a structure more defective than that of the primary peak (200) with $T_{\mathrm{S}} 200^{\circ} \mathrm{C}$. In order to uniformly deposit a larger substrate in Part 4 , the thickness is reduced to about $20 \mu \mathrm{m}$ because the sample is rotationally deposited at $T_{\mathrm{s}} 200^{\circ} \mathrm{C}$, and the distance between the substrate and the rotary axis is increased. The undoped CsI film shows a primary peak (200). 


\subsubsection{XRD of CsI:Na Film}

The CsI:Na(1\%) films deposited without heating in Part 1 also have the primary peak (211), which belongs to a poor crystalline structure due to the relatively rough structure as compared with the undoped CsI film. With the increase in the deposition rate from 30 to $110 \mathrm{~nm} / \mathrm{sec}$ in Part 2, they almost belong to the primary peak (310) because the higher deposition rate somewhat increases the condensation energy of the film.

In Part 3, CsI:Na(1\%) film of thickness larger than $70 \mu \mathrm{m}$ deposited at $T_{\mathrm{s}} 150{ }^{\circ} \mathrm{C}$ has a primary peak (200). With the increase $\mathrm{T}_{\mathrm{S}}$ to $200^{\circ} \mathrm{C}$, the $\mathrm{CsI}: \mathrm{Na}(1 \%)$ and $\mathrm{CsI}: \mathrm{Na}(2 \%)$ films have a primary peak (310). In Part 4, about $20 \mu \mathrm{m}$ of the CsI:Na(1\%) and (2\%) films deposited at $T_{\mathrm{s}} 170$ or $200{ }^{\circ} \mathrm{C}$ also have a primary peak (310). That is, the thermal condensation energy enhances the peak (310) growth.

Figure 9 shows the XRD pattern of the films doped with various Na concentrations deposited at $T_{\mathrm{s}} 200{ }^{\circ} \mathrm{C}$. The undoped CsI and CsI:Na(0.5\%) films have a strong (200) primary peak and a weak primary peak (310) at $2 \theta=64^{\circ}$ shown in Figure 9b. However, the Na dopant inhibits the (200) peak and enlarges the primary peak (310) in the $\mathrm{CsI}: \mathrm{Na}(1 \%)$ film, as shown in Figure 9c. This tendency shows that the Na dopant seemingly makes the CsI crystalline. In Figure 9d, the (310) crystalline transform effect decreases with increasing the amount of $\mathrm{NaI}$ co-evaporated to $2 \mathrm{wt}$.\%. Simultaneously, the (200) peak may disappear, but the small peaks (110) and (211) appear. As mentioned above, sufficient condensation energy from the high deposition rate or substrate temperature $\left(200^{\circ} \mathrm{C}\right)$ is an important factor in the transformation to the (310) crystalline structure for the CsI: $\mathrm{Na}(1 \%)$ films.

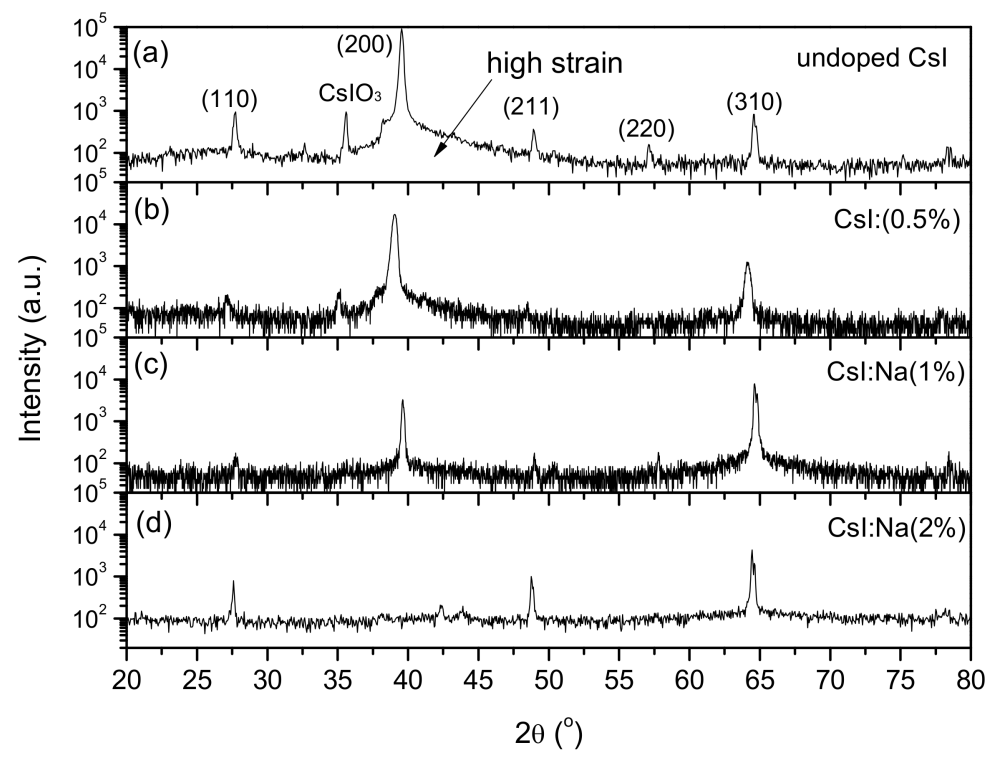

Figure 9. XRD patterns of (a) undoped CsI film, (b) CsI:Na(0.5\%) film, (c) CsI:Na(1\%) film, and (d) CsI: $\mathrm{Na}(2 \%)$.

The average crystallite size is calculated by using the Debye-Scherrer equation [46] as follows:

$$
D=k \lambda /\left(\beta_{\mathrm{hkl}} \cos \theta\right)
$$

where $D$ is the volume-weighted crystallite size, $\mathrm{k}$ is the shape factor 0.89 , and $\lambda$ is the wavelength of $\mathrm{CuK} \alpha \mathrm{X}$-ray radiation, $\beta_{\mathrm{hkl}}$ is the full width at half maximum (FWHM) of the XRD peak, and $\theta$ is the Bragg angle. From the calculations of all samples, the average crystallite sizes of CsI thin films are in the range of 40 to $50 \mathrm{~nm}$.

The XRD pattern in Figure 9 represents the vertical axial scale with log 10 for clearly illustrating the other small XRD signals. At first, the $\mathrm{CsIO}_{3} \mathrm{XRD}$ peak appears for the CsI film as oxygen species 
react with CsI during deposition because of the absorption of molecular $\mathrm{H}_{2} \mathrm{O}$. Since the surface is protected by the parylene- $\mathrm{N}$ layer, there is no $\mathrm{Cs}_{2} \mathrm{O}$ at $2 \theta=51^{\circ}$ in the XRD pattern [45].

\subsubsection{The Strain of CsI:Na Film}

The XRD curve can also be used to determine the residual stress and strain of the film by XRD offset from its corresponding crystal data, which indicates that uniform stress is generated in the film because of thermal evaporation. Figure 9 a shows a little high-strain shoulder at $2 \theta=42^{\circ}$, which has been formed in the prepared undoped CsI film shown at the boundary of the substrate in Figure $3 b$. The high strain may cause cracks on the surface, as shown in Figure 4. However, the Na dopant decreases the strain and the intensity of the (200) peak, as shown in Figure 9b-d, because of the high hygroscopicity in the air. The optimum crystalline form, $\mathrm{CsI}: \mathrm{Na}(1 \%)$, has the smallest (200) and highest (310) peaks among the samples, which may result from the lattice parameters of NaI $6.47 \AA$, which is larger than that of CsI $4.57 \AA$ at room temperature, according to the Landolt-Bornstein tables [47].

\subsection{Analysis of PL and XL Illumination by Energy Band Path}

To sum up the PL and XL experimental results, STE and defect bands co-exist for the undoped CsI film, in addition to the conduction band and the exciton levels in Figure 10a. The defect band has a larger width because the imperfect film in the natural environment and STE is formed by a specific $\mathrm{I}_{2}{ }^{-}$ center. Sodium activators produce energy levels after Na doping in CsI film as shown in Figure 10b. Paths 1 and 2 represent the electrons excited in PL and XL, respectively.

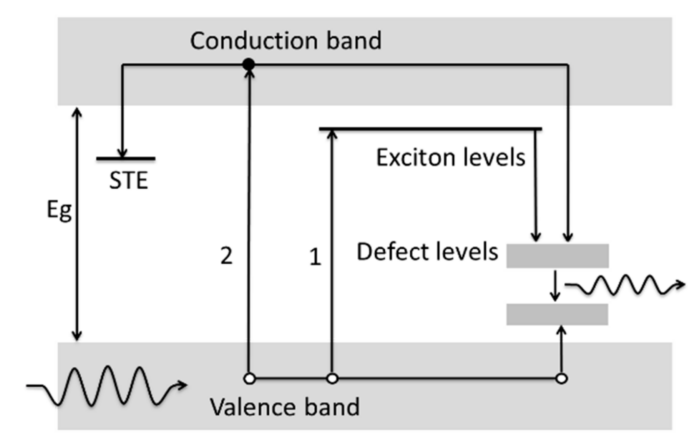

(a)

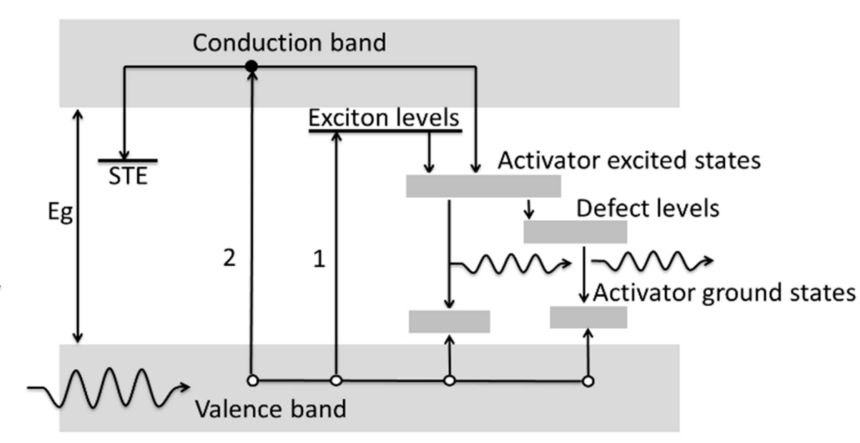

(b)

Figure 10. Schematic of PL and XL energy band structures corresponding to (a) undoped CsI film and (b) CsI:Na films irradiated with UV light (path 1) and X-ray (path 2).

\subsubsection{Fluorescence Spectrometry of UV Luminescence}

The photon energy of the UV light at $5 \mathrm{eV}$ is lower than that of $\mathrm{CsI}$ at $6.2 \mathrm{eV}$, and the electrons cannot reach the conduction band and STE position via the conduction band. However, an exciton level is produced in the polycrystalline CsI film because of the intrinsic defect produced in the deposition of the undoped CsI film [48]. The UV light could excite the electrons to the exciton level. Its energy sufficiently excites the electrons to the exciton level via Path 1 in Figure 10a. The thermalized electrons then de-excite from the defect band in a deep trap near the middle of the forbidden gap and the shallow trap close to the edges of the forbidden gap to the valence band. They are attracted by holes back into the valence band to emit light at $400 \mathrm{~nm}$ of the slow component [49].

When $\mathrm{Na}$ is doped into the CsI films, the excitation light of the CsI:Na is also at $400 \mathrm{~nm}$, but their luminance intensities are much greater than that of undoped CsI film. This is because sodium fills the defects and enhances the luminescence intensity [50]. An additional activator-excited state is generated between the exciton and the defect levels, as shown in Figure 10b. The thermal activation hopping of the STE causes photon energy to transfer from the host CsI material to the Na nanoparticles at the excited state, which results in the enhancement of Na-related luminescence at $400 \mathrm{~nm}$ [51]. 
The luminescence of CsI: $\mathrm{Na}(1 \%)$ film has the largest intensity among the samples because of the optimal Na dopant in the CsI film, as shown in Figure 11. The excess dopant Na contrarily inhibits the luminescence intensity, as in the sample $\mathrm{CsI}: \mathrm{Na}(2 \%)$.

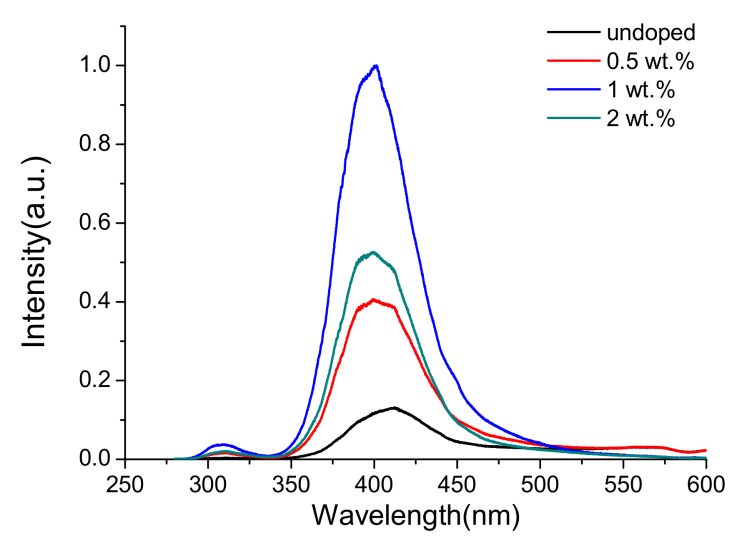

Figure 11. PL spectra of CsI:Na thin films with different dopant concentrations.

However, about $310 \mathrm{~nm}$ fluorescence correlated with the intensity of the fast component is still detected because a small number of electrons, which are in the excited state before irradiation due to the natural undoped film's property, have enough energy to switch to the conduction band and emit light through the intrinsic STE band [49]. The $310 \mathrm{~nm}$ component is intrinsic to the STEs, and the $400 \mathrm{~nm}$ peak is produced by the radiative transition from the activator-excited state to its ground state, as studied by Sawant et al. [50].

\subsubsection{Fluorescence Spectrometry of X-ray Luminescence}

The X-ray of 0.15404 and $0.15446 \mathrm{~nm}$ is used for excitation in the XL experiment. The photon energy of about $8 \mathrm{keV}$ is much greater than that of the CsI bandgap. Upon irradiation of the films with the high-energy light, a large number of electrons absorb sufficient photon energy to reach the conduction band via Path 2 in Figure 10 and freely move in the conduction band. In undoped CsI films, some of the electrons move to STE and increase the $315 \mathrm{~nm}$ emission, as shown in Figure 12. The fluorescence excitation in XL becomes much higher than the excitation in PL.

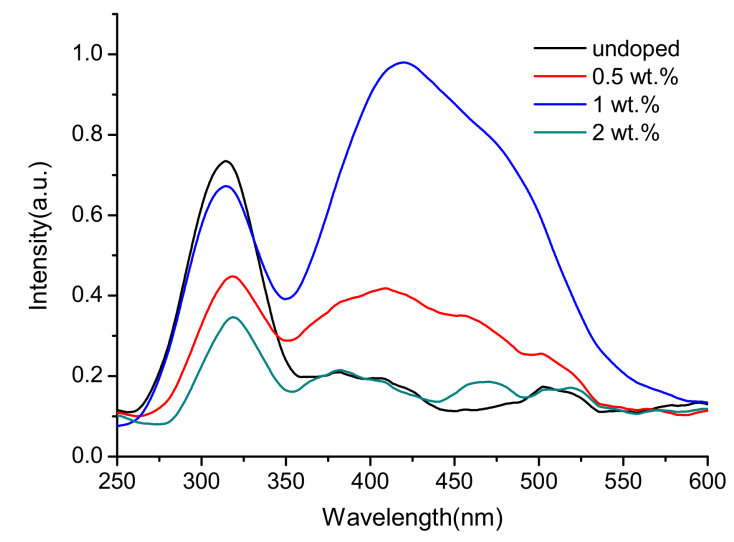

Figure 12. XL spectra of CsI:Na thin films with different dopant concentrations.

When CsI:Na films are irradiated with X-ray, the $315 \mathrm{~nm}$ intensity somewhat decreases with an increase in the amount of Na dopant. In contrast, the additional luminescence peaks at $420 \mathrm{~nm}$, which forms through activator-excited states caused by the Na dopant, increases as the Na dopant increases for the CsI: $\mathrm{Na}(0.5 \%)$ sample. The luminescence of the undoped sample is the weakest, and that of 
the CsI: $\mathrm{Na}(1 \%)$ is the strongest. The excess $\mathrm{Na}$-doped sample CsI:Na(2\%) inversely decreases the luminescence. These results confirm that the emission intensities of $\mathrm{Na}$-doped films are greater than that of the undoped CsI film. Moreover, a shoulder luminescence peak at about $450 \mathrm{~nm}$ shown in Figure 12 corresponds to the other defect level, which is also produced by the Na dopant. The trend in intensity change is similar to that at $420 \mathrm{~nm}$.

The wavelength of $420 \mathrm{~nm}$ is longer than $400 \mathrm{~nm}$ with irradiation by the $275 \mathrm{~nm}$ UV light, although the excitation photon energy of the X-rays is much larger than the UV light. The electrons absorb higher energy when irradiated by X-rays. They hop farther through thermalization to the higher excited state, which is conversely closer to the ground state for de-excitation. That results in the luminescence wavelength in XL being longer than that in PL [28]. This phenomenon is discussed in the section below.

\subsubsection{Comparison of PL and XL}

Figure 13 schematically illustrates the luminescence principle by a potential energy diagram. According to the Frank-Condon principle, the electrons absorb the energy of the excitation light, resulting in a vertical transition from the ground state to the excited state without any change in configurational coordinate $X$, which is the mean distance between the luminescence centers and surrounding ions.

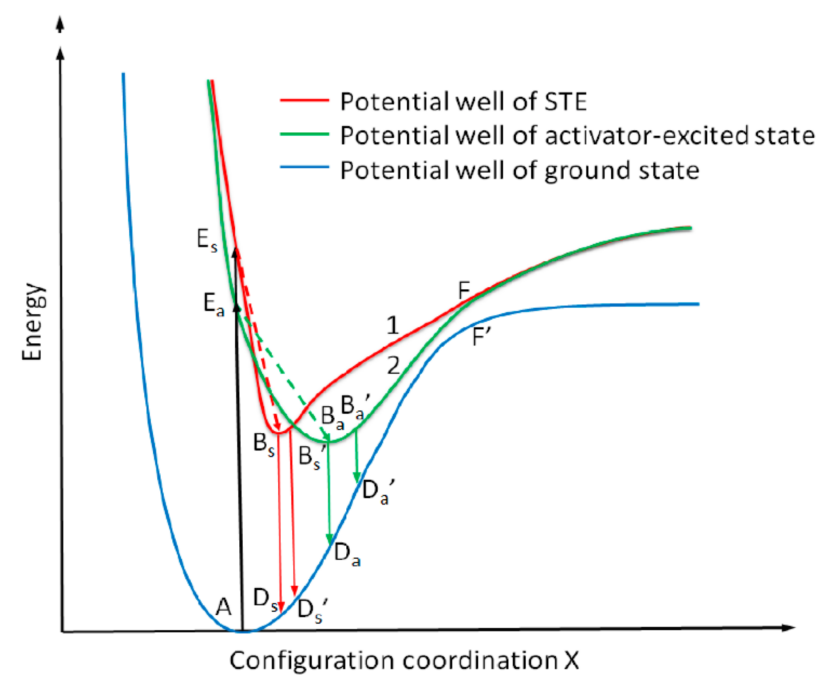

Figure 13. Schematic diagram of the ground state and excited states of the luminescent centers. Configuration coordinate $X$ is the mean distance between the luminescence centers and the surrounding ions.

The electron relaxes toward the minimum energy state through the thermalization process. The electron returns to the ground state through two possible processes: (1) emitting lower-energy photons with respect to excitation through a radiative process and (2) non-radiative process if the electron absorbs thermal energy to reach point $F$ at potential curves of the excited states, which is near point $\mathrm{F}$ at the ground potential curve of the ground state [27].

The potential energies of the ground and excited states are described with two excited states in Figure 13. If the luminescence center is in the STE state, then the excited electron only moves from A to $E_{S}$ and $B_{S}$ of the minimal potential in PL by irradiating the lower-photon-energy UV. The emitted photo-energy of fluorescence through de-excitation to point $D_{\mathrm{S}}$ is

$$
h \omega_{\mathrm{PL}} \cong E_{\mathrm{S}}-E_{\mathrm{ex}}
$$

where $E_{\mathrm{S}}$ is the energy gap thermalized from the conduction band to the STE, and $E_{\mathrm{ex}}$ is the bounding energy of excitation. In $\mathrm{XL}$, the higher photon energy easily excites the ground electron to the excitation 
potential $\mathrm{B}_{\mathrm{S}}$; the several $\mathrm{N}$ extra phonon-energy $h \Omega_{\text {phonon }}$ which is less than the ionization energy remains in the potential well to let the electrons move into the somewhat higher potential $\mathrm{B}_{\mathrm{S}}$ ' through the thermalization process [52]. Hence, the electron vibrates and shifts slightly to the right in the direction of $F$. The photon energy of fluorescence de-excited to $D_{\mathrm{S}}{ }^{\prime}$ is

$$
h \omega_{\mathrm{XL}} \cong E_{\mathrm{S}}-E_{\mathrm{ex}}-N h \Omega_{\text {phonon }}
$$

We found that the photon energy of fluorescence $h \omega_{\mathrm{PL}}$, with a maximum intensity of PL at $310 \mathrm{~nm}$ shown in Figure 11, is larger than that of $h \omega_{\mathrm{XL}}$. The maximum intensities of $X \mathrm{~L}$ at $315 \mathrm{~nm}$ are shown in Figure 12. A red-shift effect on XL fluorescence arises with the wavelength changes from 310 to $315 \mathrm{~nm}$ with the small shift of the electron from $B_{\mathrm{S}}$ to $B_{\mathrm{S}}{ }^{\prime}$ in the steep well as shown in line 1 in Figure 13. The potential well of the activator-excited state, shown in line 2 in Figure 13, is broader than that of STE. The electron shifts easily from $B_{\mathrm{a}}$ to $B_{\mathrm{a}}{ }^{\prime}$ in the well. The wavelength of the red-shift effect changes from 400 to $420 \mathrm{~nm}$ as shown in Figures 11 and 12, respectively. Apparently, the red-shift in the potential well of the activator-excited state is larger than that of STE.

\section{Conclusions}

We study undoped CsI and CsI:Na films having a thickness greater than $170 \mu \mathrm{m}$. A cylindrical structure of about $3 \mu \mathrm{m}$ can be fabricated by thermal evaporation of powders from a molybdenum boat at a substrate temperature of $200{ }^{\circ} \mathrm{C}$. The visible-light luminescence of CsI:Na films is more intense than that of undoped CsI films when irradiated by X-ray. The best-performing CsI:Na film fabricated by co-evaporating CsI and $1 \mathrm{wt} . \% \mathrm{NaI}$ exhibits the best columnar structure for guiding the luminescent light and the highest visible-light luminescence intensity in the PL and XL spectra. The undoped CsI films show preferred crystal orientation at (200), and the CsI:Na films co-evaporated by $1 \mathrm{wt} . \% \mathrm{NaI}$ at (310). The protective layer of N-parylene can be subsequently deposited on the CsI:Na film in the same vacuum chamber to increase the moisture resistance of the film. The luminescence wavelength of visible light at $420 \mathrm{~nm}$ in XL is longer than that at $400 \mathrm{~nm}$ in PL due to the red-shift effect.

Author Contributions: Conceptualization, J.-C.H. and Y.-S.M.; Methodology, J.-C.H.; Validation, J.-C.H.; Formal Analysis, Y.-S.M.; Investigation, Y.-S.M.; Resources, J.-C.H.; Data Curation, J.-C.H.; Writing-Original Draft Preparation, J.-C.H. and Y.-S.M.; Writing-Review and Editing, J.-C.H.; Supervision, J.-C.H.; Project Administration, J.-C.H. and Y.-S.M.; Funding Acquisition, J.-C.H.

Funding: This research was funded by the Ministry of Science and Technology of Taiwan, grant number MOST 106-2221-E-030-007-MY3 and MOST 106-2112-M-030-001.

Conflicts of Interest: The authors declare no conflict of interest.

\section{References}

1. Breskin, A. CsI UV photocathodes: History and mystery. Nucl. Instrum. Meth. A 1996, 371, 116-136. [CrossRef]

2. Simons, D.G.; Fraser, G.W.; De Korte, P.A.J.; Pearson, J.F.; De Jong, L. UV and XUV quantum detection efficiencies of CsI-coated microchannel plates. Nucl. Instrum. Meth. A 1987, 261, 579-586. [CrossRef]

3. Seltzer, S.M.; Berger, M.J. Evaluation of the collision stopping power of elements and compounds for electrons and positrons. Int. J. Appl. Radiat. Isot. 1982, 33, 1189-1218. [CrossRef]

4. Boutboul, T.; Akkerman, A.; Breskin, A.; Chechik, R. Electron inelastic mean free path and stopping power modeling in alkali halides in the $50 \mathrm{eV}-10 \mathrm{keV}$ energy range. J. Appl. Phys. 1996, 79, 6714-6721. [CrossRef]

5. Kubota, S.; Sakuragi, S.; Hashimoto, S.; Ruan, J.Z. A new scintillation material: Pure CsI with 10 ns decay time. Nucl. Instrum. Meth. Phys. Res. A 1988, 268, 275-277. [CrossRef]

6. Menefee, J.; Cho, Y.; Swinehart, C. Sodium activated cesium iodide as a gamma ray and charge particle detector. IEEE Trans. Nucl. Sci. 1967, 14, 464-467. [CrossRef]

7. Kowalski, M.P.; Fritz, G.G.; Cruddace, R.G.; Unzicker, A.E.; Swanson, N. Quantum efficiency of cesium iodide photocathodes at soft X-ray and extreme ultraviolet wavelengths. Appl. Opt. 1986, 25, 2440-2446. [CrossRef] 
8. Mikhailik, K.V.; Kapustyanyk, V.; Tsybulskyi, V.; Rudyk, V.; Kraus, H. Luminescence and scintillation properties of CsI-A potential cryogenic scintillator. Phys. Status Solidi B 2015, 252, 804-810. [CrossRef]

9. Nishimura, H.; Sakata, M.; Tsujimoto, T.; Nakayama, M. Origin of the 4.1-eV luminescence in pure CsI scintillator. Phys. Rev. B 1995, 51, 2167-2172. [CrossRef]

10. Yang, P.; Harmon, C.D.; Doty, F.P.; Ohlhausen, J.A. Effect of humidity on scintillation performance in Na and Tl activated CsI crystals. IEEE Trans. Nucl. Sci. 2014, 61, 1024-1031. [CrossRef]

11. Von der Weid, J.P. ; Aegerter, M.A. Magneto-optical effects on the emission of self-trapped exciton perturbed by Na impurity in CsI:Na crystal. J. Lumin. 1979, 18, 858-862.

12. Liu, F.; Ouyang, X.; Tang, M.; Xiao, Y.; Liu, B.; Zhang, X.; Feng, Y.; Zhang, J.; Liu, J. Scaling-induced enhancement of X-ray luminescence in CsI(Na) crystals. Appl. Phys. Lett. 2013, 102, 181107. [CrossRef]

13. Jammal, N.; Rai, R.; Singh, B.K. Structural and optical properties of CsI thin films: Influence of film thickness and humidity. Phys. B Condens. Matter. 2018, 546, 21-27. [CrossRef]

14. Zeng, Y.S. The Fluorescence Luminescence Efficiency and X-ray Image Analysis of the Sodium-Doped Cesium Iodide Thin Films Irradiated by UV Light and X-ray. Master's Thesis, Fu Jen Catholic University, New Taipei City, Taiwan, 2017.

15. Hsieh, C.C. The Fluorescence Luminescence Efficiency and Anti-Deliquescence of CsI(Na) Film Protected by Organic Film. Master's Thesis, Fu Jen Catholic University, New Taipei City, Taiwan, 2015.

16. Chu, C.H. The Fluorescence Luminescence Efficiency by UV Light and X-ray of the Scintillator Sodium-Doped Cesium Iodide Thin Films. Master's Thesis, Fu Jen Catholic University, New Taipei City, Taiwan, 2014.

17. Lu, C.C. The Luminescence-Energy Efficiency and Anti-Deliquesce of CsI, NaI and Their Mixture Films. Master's Thesis, Fu Jen University, New Taipei City, Taiwan, 2019.

18. Jenkins, R.; Fawcett, T.G.; Smith, D.K.; Visser, J.W.; Morris, M.C.; Frevel, L.K. JCPDS—international centre for diffraction data sample preparation methods in X-Ray Powder Diffraction. Powder Diffr. 1986, 1, 51-63. [CrossRef]

19. Chen, H.L.; Hsu, J.C.; Lin, Y.H. Luminescence efficiency and optical property of CsI and NaI films. In Proceedings of the 51st SVC Annual Technical Conference, Chicago, IL, USA, 21-22 April 2008.

20. Hsu, J.C.; Lu, C.C.; Wang, P.W.; Chen, H.L.; Yu, J.C. The luminescence-energy efficiency and anti-deliquesce of CsI, NaI and the mixture films. In Proceedings of the ISSP2009: 10th International Symposium on Sputtering \& Plasma Processes, Kanagawa, Japan, 8-10 July 2009.

21. Menge, P.R. Scintillation Pixel Design and Method of Operation. U.S. Patent 8,324,583, 4 December 2012.

22. Nitti, M.A.; Cioffi, N.; Nappi, E.; Singh, B.K.; Valentini, A. Influence of bias voltage on the stability of CsI photocathodes exposed to air. Nucl. Instr. Meth. A 2002, 493, 16-24. [CrossRef]

23. Shahova, K.V.; Panova, A.N.; Goriletsky, V.I.; Prikhod'ko, Y.A.; Gavrylyuk, V.P.; Korsunova, S.P.; Kosinov, N.N. Luminescence and scintillation properties of Na-activated CsI-CsBr crystals. Radiat. Meas. 2001, 33, 769-771. [CrossRef]

24. Keillor, M.E.; Cooper, M.W.; Hayes, J.C.; McIntyre, J.I. Degradation of $81 \mathrm{keV} 133$ Xe gamma-rays into the 31 keV X-ray peak in CsI scintillators. J. Radioanal. Nucl. Chem. 2009, 282, 699-702. [CrossRef]

25. Crannell, C.J.; Kurz, R.J.; Viehmann, W. Characteristics of cesium iodide for use as a particle discriminator for high-energy cosmic rays. Nucl. Instr. Meth. 1974, 115, 253-261. [CrossRef]

26. Rodnyi, P.A. Physical Processes in Inorganic Scintillators; CRC Press: Boca Raton, FL, USA, 1997; Volume 14.

27. Bergenius, S. GLAST CsI (Tl) Crystals. Ph.D. Thesis, Aarhus University, Aarhus, Denmark, 2004.

28. Birks, J.B. The Theory and Practice of Scintillation Counting: International Series of Monographs in Electronics and Instrumentation; Elsevier: Amsterdam, The Netherlands, 1997; Volume 27.

29. Song, K.S.; Williams, R.T. Self-Trapped Excitons; Springer: New York, NY, USA, 1996; Volume 105.

30. Ong, C.K.; Song, K.S.; Monnier, R.; Stoneham, A.M. Electronic structure and luminescence of CsI: Na. J. Phys. C 1979, 12, 4641. [CrossRef]

31. Pai, D.M.; Enck, R.C. Onsager mechanism of photogeneration in amorphous selenium. Phys. Rev. B 1975, 11, 5163. [CrossRef]

32. Lu, X.; Li, Q.; Bizarri, G.A.; Yang, K.; Mayhugh, M.R.; Menge, P.R.; Williams, R.T. Coupled rate and transport equations modeling proportionality of light yield in high-energy electron tracks: CsI at $295 \mathrm{~K}$ and $100 \mathrm{~K}$; CsI: Tl at 295 K. Phys. Rev. B 2015, 92, 115207. [CrossRef]

33. Hsu, O.L.; Bates, C.W., Jr. Luminescence phenomena In Cs:Na. J. Lumin. 1975, 11, 65-74. [CrossRef] 
34. Hu, J.P.; Liu, F.; Ouyang, X.P. The CL and PL characteristic of different scale CsI: Na crystals. arXiv 2014, arXiv:1408.4212.

35. Yakovlev, V.; Trefilova, L.; Meleshko, A.; Ganja, Y. Short-living absorption and emission of CsI(Na). J. Lumin. 2011, 131, 2579-2581. [CrossRef]

36. Jing, T.; Cho, G.; Drewery, J.; Fujieda, I.; Kaplan, S.N.; Mireshghi, A.; Perez-Mendez, V.; Wildermuth, D. Enhanced columnar structure in CsI layer by substrate patterning. IEEE Trans. Nucl. Sci. 1992, 39, 1195-1198. [CrossRef]

37. Ma, Y.S.; Hsu, J.C.; Liu, C.P.; Chen, H.L. Fabrication of columnar CsI and CsI: Na scintillation films deposited by vacuum thermal evaporation at high deposition rates. Vacuum 2015, 122, 96-102. [CrossRef]

38. Kramer, P.; Sharma, A.K.; Hennecke, E.E.; Yasuda, H. Polymerization of para-xylylene derivatives (parylene polymerization). I. Deposition kinetics for parylene N and parylene C. J. Polym. Sci. 2003, 22, 475-491. [CrossRef]

39. Marszalek, T.; Gazicki-Lipman, M.; Ulanski, J. Parylene C as a versatile dielectric material for organic field-effect transistors. Beilstein J. Nanotechnol. 2017, 8, 1532-1545. [CrossRef]

40. Thornton, J.A. Influence of apparatus geometry and deposition conditions on the structure and topography of thick sputtered coatings. J. Vac. Sci. Technol. 1974, 11, 666-670. [CrossRef]

41. Sharifi, H.; Lahiji, R.R.; Lin, H.C.; Peide, D.Y.; Katehi, L.P.; Mohammadi, S. Characterization of Parylene-N as flexible substrate and passivation layer for microwave and millimeter-wave integrated circuits. IEEE Trans. Adv. Pack. 2009, 32, 84-92. [CrossRef]

42. Kinosita, K.; Nishibori, M. Porosity of $\mathrm{MgF}_{2}$ films-evaluation based on changes in refractive index due to adsorption of vapors. J. Vac. Sci. Technol. 1969, 6, 730-733. [CrossRef]

43. Atanassov, G.; Thielsch, R.; Popov, D. Optical properties of $\mathrm{TiO}_{2}, \mathrm{Y}_{2} \mathrm{O}_{3}$ and $\mathrm{CeO}_{2}$ thin films deposited by electron beam evaporation. Thin Solid Films 1993, 223, 288-292. [CrossRef]

44. Fairchild, S.B.; Back, T.C.; Murray, P.T.; Cahay, M.M.; Shiffler, D.A. Low work function CsI coatings for enhanced field emission properties. J. Vac. Sci. Technol. A 2011, 29, 031402. [CrossRef]

45. Garg, P.; Rai, R.; Singh, B.K. Structural characterization of "as-deposited" cesium iodide films studied by X-ray diffraction and transmission electron microscopy techniques. Nucl. Instrum. Meth. Phys. Res. A 2014, 736, 128-134.

46. Patterson, A.L. The Scherrer formula for X-ray particle size determination. Phys. Rev. 1939, 56, 978. [CrossRef]

47. Pies, W.; Weiss, A. Landolt-Bornstein tables. In Crystal Structure Data of Inorganic Compounds; Hellwege, K.H., Hellwege, A.M., Eds.; Springer: New York, NY, USA, 1973; Landolt-Bornstein, Group III; Volume 7.

48. Ahmed, S.N. Physics and Engineering of Radiation Detection; Academic Press Inc.: Cambridge, MA, USA, 2007.

49. Moszyński, M.; Syntfeld-Każuch, A.; Swiderski, L.; Sibczyński, P.; Grodzicka, M.; Szcześniak, T.; Gektin, A.V.; Schotanus, P.; Shiran, N.; Williams, R.T. Energy resolution and slow components in undoped CsI crystals. IEEE Trans. Nucl. Sci. 2016, 63, 459-466. [CrossRef]

50. Sawant, A.; Zeman, H.; Samant, S.; Lovhoiden, G.; Weinberg, B.; DiBianca, F. Theoretical analysis and experimental evaluation of a CsI (Tl) based electronic portal imaging system. Med. Phys. 2002, 29, 1042-1053. [CrossRef]

51. Nakayama, M.; Ando, N.; Hirai, J.; Nishimura, H. Scintillation activated by nanoparticle formation in CsI:Na thin films. J. Lumin. 2004, 108, 359-363. [CrossRef]

52. Herman, M.A.; Bimberg, D.; Christen, J. Heterointerfaces in quantum wells and epitaxial growth processes: Evaluation by luminescence techniques. J. Appl. Phys. 1991, 70, R1-R52. [CrossRef]

(C) 2019 by the authors. Licensee MDPI, Basel, Switzerland. This article is an open access article distributed under the terms and conditions of the Creative Commons Attribution (CC BY) license (http://creativecommons.org/licenses/by/4.0/). 